$$
1 N-20
$$

NASA Contractor Report CR-190764

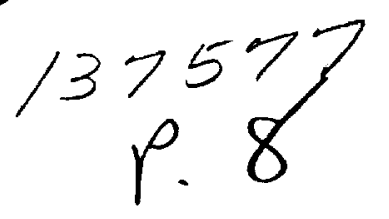

\title{
Multimegawatt Dynamic NEP PMAD Study
}

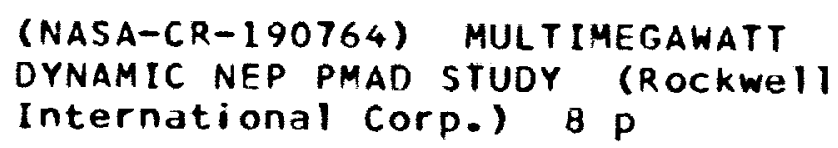

N93-16626

Unclas

$63 / 20 \quad 0137577$

\section{Kenneth J. Metcalf}

Rockwell International Corporation

Rocketdyne Divsion

Canoga Park, California

November 1992

Prepared for

Lewis Research Center

Under Contract NAS. 3-25808

\section{NASA \\ National Aeronautics and Space Administration}


Log Nr. 030

\title{
MULTIMEGAWATT DYNAMIC NEP PMAD STUDY
}

\author{
Kenneth J. Metcalf \\ Rocketdyne Division \\ Rockwell International Corporation \\ 6633 Canoga Avenue \\ P.O. Box 7922 \\ Canoga Park, CA 91309-7922 \\ (818) 718-3391
}

CAMERA READY MANUSCRIPT prepared for:

Tenth Symposium

on Space Nuclear Power and Propulsion

Albuquerque, New Mexico

10-14 January 1993

initial submission: 19 June 1992

final submission: 16 October 1992

Author to whom correspondence should be sent: Kenneth J. Metcalf 


\title{
MULTIMEGAWATT DYNAMIC NEP PMAD STUDY
}

\author{
Kenneth J. Metcalf \\ Rocketdyne Division \\ Rockwell International Corporation \\ 6633 Canoga Avenue \\ P.O. Box 7922, MZ HB05 \\ Canoga Park, CA 91309-7922 \\ (818) 718-3391
}

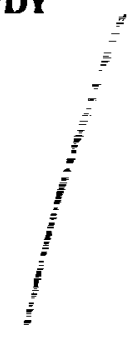

\begin{abstract}
The National Aeronatutics and Space Administration Lewis Research Center (NASA LeRC) is developing a Fortran-based model of a complete nuclear electric propulsion (NEP) vehicle to be used for piloted or cargo missions to the Moon or Mars. The proposed vehicle will use either a Brayton or K-Rankine power conversion cycle, and either ion or magnetoplasmadynamic (MPD) thrusters. In support of this effort, Rocketdyne evaluated various power management and distribution (PMAD) approaches and selected a low-frequency design that is based on the direct use of the alternator voltage and frequency for power transmission. This approach was compared with dc and high-frequency ac designs, and selected on the basis of mass, efficiency, and qualitative assessments of power quality, reliability and development costs. This low-frequency architecture will be used as the reference in future NEP PMAD studies and for the subsequent Fortran model development.
\end{abstract}

\section{INTRODUCTION}

A study was performed under the direction of NASA LeRC to assess various power management and distribution (PMAD) approaches for nuclear electric propulsion (NEP) vehicles and to identify preferred designs for characterization. This PMAD evaluation built on the results of a prior solar and NEP PMAD study (Meisner 1991) and considered factors such as system mass, efficiency, reliability, safety, controllability, power quality, and technology status. Because proposed NEP vehicles will be used for piloted and cargo missions to the Moon and Mars, the PMAD systems must be designed for environments ranging from Low Earth Orbit (LEO $=407.5 \mathrm{~km}$ ) to Mars obit. The NEP vehicle designs under study used either K-Rankine or Brayton power conversion cycles to drive three-phase rotary alternators. Power will be supplied to either ion or magnetoplasmadynamic (MPD) thrusters. The ion and MPD thruster characteristics were provided to Rocketdyne by the Nuclear Propulsion Office of NASA LeRC (Gilland and Meyers 1990).

The top level NEP requirements were defined by NASA's Nuclear Propulsion Office and they were used to define the PMAD system requirements. Because the purpose of NASA LeRC's modelling efforts was to assess various power system options and identify an optimum NEP power system design, the PMAD models had to cover a wide range of operating conditions. The model that would ultimately be developed for the selected PMAD approach would need to operate within the context of an overall NEP power system model. With this purpose in mind, NASA LeRC specified the following PMAD model requirements.

- Technology Time Frame: 2005 to 2020,

- Operating environment: LEO $(400 \mathrm{~km})$ to Interplanetary Space,

- System Operating Lifetime: 2 to 10 years,

- System Power Level: $100 \mathrm{kWe}$ to $10 \mathrm{MWe}$,

- Voltage Level: 200 to $10,000 \mathrm{~V}$,

- DC and AC Frequency Range: $400 \mathrm{~Hz}$ to $20 \mathrm{kHz}$,

- Vehicle Dimensions (Transmission Length): 25 to $300 \mathrm{~m}$, and

- Coldplate Temperature Range: 333 to $473 \mathrm{~K}$.

Because of the interest in high-temperature (HT) electronics, NASA wanted to be able to assess their impact on the power system. Generally a component designed for high-temperature operation is less efficient than one designed for lower temperatures. This occurs because the resistivity of almost all elements, conductors, transformer windings, switches, diodes, and other components rises with temperature. The only exception is that transformer core losses decline with temperature. Because of this effect, algorithms were developed to adjust component efficiency with temperature. Higher component operating temperatures are being investigated because they reduce the mass of the electronics radiators. The electronics radiator calculations use the component coldplate temperature, so the radiator area and mass are automatically recalculated when the 
coldplate temperature is changed. The reduction in component efficiency causes the PMAD system end-to-end efficiency to decline. This necessitates a larger power source to compensate. The resulting increase in power source mass may offset the reduction in electronics radiator mass. The algorithms that were incorporated into these models addressed this trade off and allowed the user to draw initial conclusions about the best operating temperature for the electronics.

Two thruster types are being considered for NEP vehicles; consequently, the PMAD models had to be flexible enough to allow the user to evaluate either type. This necessitated two power processing unit (PPU) designs. The ion PPU contains four power supplies, beam, discharge, accelerator, and neutralizer. Top-level power and voltage parametrics are shown in Table 1 for these power supplies. Note, the bulk of the power is processed by the beam power supply and it is used directly for thrust. The other power supplies provide the proper voltage biases between the thruster elements and neutralize the ionized thruster output. The MPD PPU is much simpler and it only has one power supply that provides a nominal voltage of $300 \mathrm{Vdc}$. Both thrusters can tolerate relatively high levels of voltage ripple and electromagnetic interference. Based on this information, a default ripple value of $5 \%$ was input into both models.

TABLE 1. Ion PPU Power Supply Parameters.

\begin{tabular}{lcc}
\hline Power Supply & $\begin{array}{c}\text { Power Processing } \\
\text { Percentage (\%) }\end{array}$ & $\begin{array}{c}\text { Nominal Voltage } \\
\text { Level (Vdc) }\end{array}$ \\
\hline Beam & 96.29 & 1800 \\
Discharge & 3.6 & 30 \\
Accelerator & 0.1 & 500 \\
Neutralizer & 0.01 & 20 \\
\hline
\end{tabular}

\section{VERSUS AC POWER TRANSMISSIQN}

Two basic power transmission methods ( $\mathrm{dc}$ and ac) were evaluated for the NEP vehicle on the basis of mass, efficiency, reliability, and development costs. Figure 1 compares the basic operating steps employed in these two approaches. The dc approach would use a rectifier immediately following the alternator to convert the alternator's ac output into dc. A dc transmission line would then carry this power to the PPUs located next to the thrusters. Within the PPUs, a chopper converts the dc into high-frequency ac so that a subsequent transformer can step down the high transmission line voltage to a level suitable for the thrusters. The lower voltage ac is then converted into dc for the thrusters.

\section{Power Transmission Block Diagram}

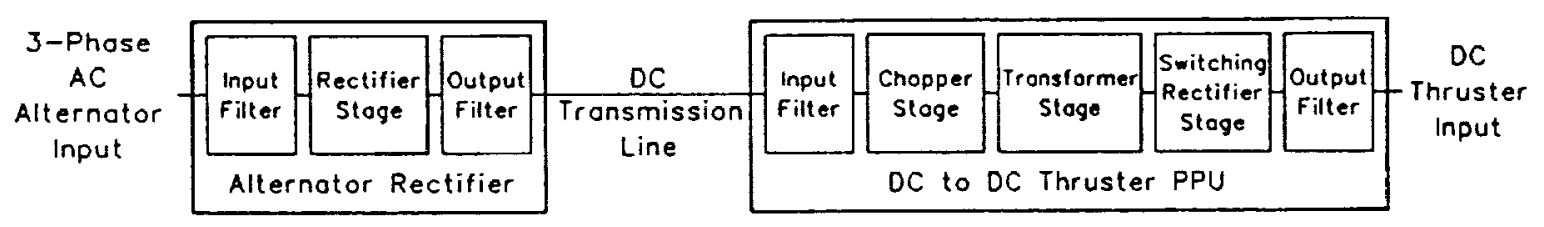

AC Power Transmission Block Diagram

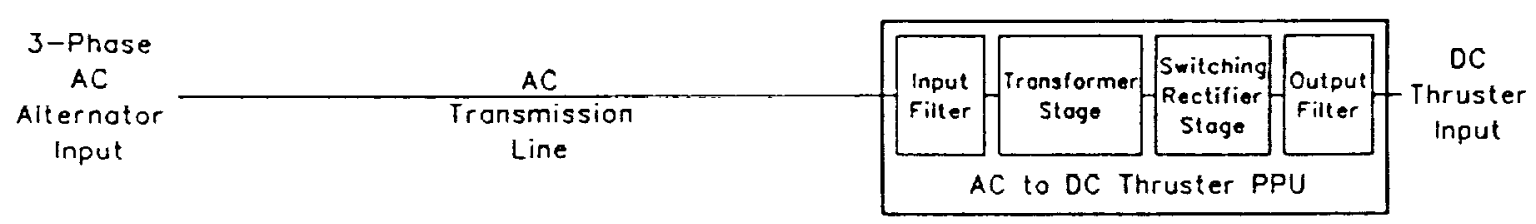

FIGURE 1. DC versus AC NEP Vehicle PMAD Comparison. 
It is possible to design a simpler transmission system based directly on the alternator three-phase ac output. If a high-voltage alternator design is used, power can be efficiently conducted from the altemator to the PPUs using an ac transmission line. Within the PPUs, a transformer steps the high-voltage ac down and a rectifier converts it into dc for the thrusters.

Comparing the two approaches, it is apparent that the dc system is much more complex. This leads to mass, efficiency, and reliability penalties. Key PMAD parameters are compared in Table 2 for the two approaches. Although the dc system is notably heavier, the mass difference would be even larger except for the fact that the chopper in the dc-to-dc PPU operates at a high frequency. This reduces the subsequent PPU transformer and filter masses, and improves the quality of the power provided to the thruster. However, there are disadvantages associated with the use of complex dc-to-dc converters instead of transformers. The added conversion steps substantially lower the end-to-end PMAD efficiency. This means a larger power source is needed to offset the losses. The dc system development and hardware costs are also probably higher, and the added conversion steps will tend to reduce system reliability. In fact because of the megawatt power levels, the chopper stage in the dc-to-dc PPU would probably be a high-risk development item.

TABLE 2. DC versus AC Comparison for Ion and MPD Thrusters. ${ }^{2}$

\begin{tabular}{lccccc}
\hline & \multicolumn{2}{c}{$\begin{array}{c}\text { Low-Frequency Transmission } \\
\text { (Alternator Frequency) }\end{array}$} & & \multicolumn{2}{c}{$\begin{array}{c}\text { DC Power } \\
\text { Transmission }\end{array}$} \\
\cline { 2 - 3 } \cline { 5 - 6 } Parameter & Ion & MPD & & Ion & MPD \\
\hline Mass & $48,350 \mathrm{~kg}$ & $50,450 \mathrm{~kg}$ & & $64,080 \mathrm{~kg}$ & $65,170 \mathrm{~kg}$ \\
& $1.68 \mathrm{~kg} / \mathrm{kWe}$ & $1.75 \mathrm{~kg} / \mathrm{kWe}$ & & $2.32 \mathrm{~kg} / \mathrm{kWe}$ & $2.36 \mathrm{~kg} / \mathrm{kWe}$ \\
Efficiency (\%) & 95.0 & 95.1 & & 88.9 & 89.0 \\
Power Quality & Good & Good & & Excellent & Excellent \\
Complexity & Low & Low & & High & High \\
\hline
\end{tabular}

PMAD values based on three channels providing a total of $30 \mathrm{MWe}, 150$ meter main transmission line length, $8000-\mathrm{V}$ transmission voltage, and $100^{\circ} \mathrm{C}$ electronics coldplate temperature.

The chopper stage switches dc power at a high rate to generate an alternating voltage and current. High-frequency ac is generated to reduce the mass of the subsequent transformer. Switch synchronization is critical in a chopper, but it can be quite difficult in a high-power, high-voltage chopper because numerous switches must be paralleled or connected in series to handle the high current and/or voltage levels. If an individual switch fails to operate properly, it can result in an internal short and cause the switch at fault to fail. To reduce the chances of this occurring, special circuits force the switches to load share, and snubbers are used to protect against voltage spikes. While they can be very effective, they add to the mass of the chopper. Due to these problems, there are programs currently in progress to develop higher power and voltage switching devices that are rugged and have improved switching characteristics. The development of these devices is crucial to the fabrication of a dc-to-dc converter rated for megawatt power levels.

Although not shown in Figure 1, another dc power transmission component that will require extensive development is a dc switchgear unit. The remote bus isolators (RBIs) in the dc switchgear unit must use a mechanical and/or semiconductor switch capable of interrupting the maximum calculated bus voltage. Depending on the design, these switches will draw an arc or encounter high-electromagnetic forces during opening that will generate high stresses and concentrated heating. This forces the dc RBI construction to be heavier. A comparable ac RBI switch can open during the zero current crossing. This dramatically reduces the stresses encountered and consequently its mass. At the present time, a major design issue is the development of a suitable dc RBI for the Space Station Freedom (SSF) electrical power system. The power levels on SSF are on the order of tens of kilowatts; the power levels on the proposed NEP vehicle are on the order of megawatts. Based on this comparison, a dc RBI rated for megawatt power levels would be a feasibility issue.

Based on the analysis results summarized above, ac transmission was selected over dc. It appears to have several advantages, lower development costs, higher projected component reliabilities, simplified fault protection, and a higher overall PMAD system efficiency. For a dc system to be competitive, it would need to offer substantial mass savings. This is not the case. Results to date indicate a de system would actually be heavier. 


\section{LOW-FREOUENCY VERSUS HUGH-FREQUENCY POWER TRANSMISSION}

After selecting ac power transmission, further studies were conducted to determine the best form of ac transmission. Basically two methods are available, a low-frequency approach that bases the transmission voltage and frequency on the alternator output, and a high-frequency approach that uses a frequency converter following the alternator to generate the desired high-frequency output. Diagrams for the two approaches, displaying the required components and internal conversion steps, are shown in Figure 2.

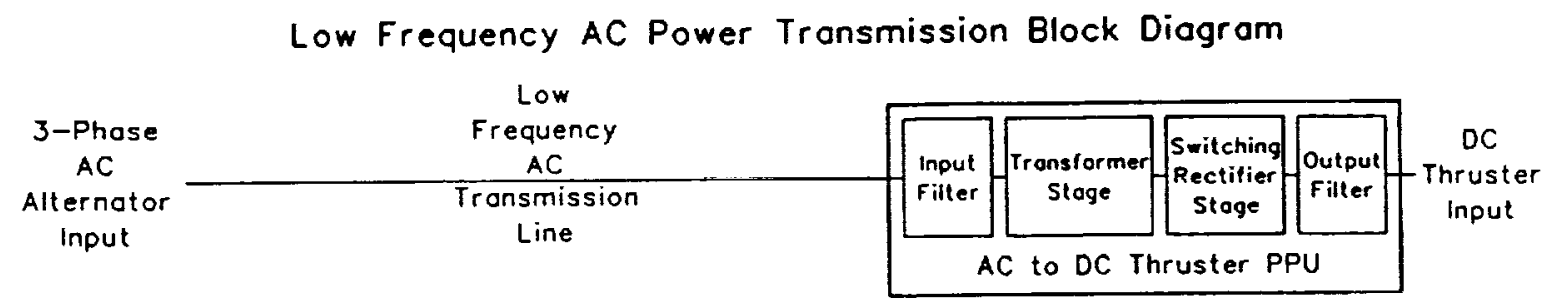

High Frequency AC Power Transmission Block Diogram

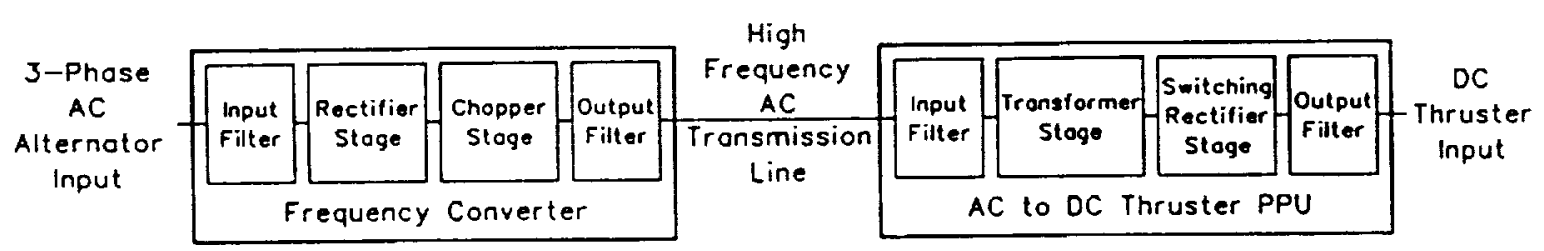

FIGURE 2. Low versus High Frequency NEP Vehicle PMAD Comparison.

The low-frequency system, because it uses the alternator voltage and frequency directly, is less complex. The three-phase ac alternator output is good for high-power delivery. A three-phase power system delivers a steadier power flow, whereas a single-phase system exhibits a pulsating power effect. Three-phase systems also have a higher power transfer capability, which promotes the design of an efficient, light weight transmission line. Finally, because the transmission frequency is relatively low, line inductance and skin effect losses are less of a problem. However, low-frequency distribution is not optimum for transformer and filter design and it causes the transformers and dc output filters located in the PPUs to be relatively heavy. Consequently, high-frequency distribution was evaluated.

The high-frequency approach uses a frequency converter following the alternator to convert the alternator's Iow-frequency output into high-frequency ac. It can be designed to provide a single- or three-phase output, and a wide range of frequencies. Hence, the number of phases and transmission frequency can be selected to yield the optimum PMAD system design. This allows significant mass savings in the PPUs due to the reduced transformer and filter mass, and because high-frequency power is easier to filter it improves the quality of the power fed to the thrusters. However, a high-frequency PMAD system has certain drawbacks. The addition of the frequency converter increases system mass, and reduces the end-to-end efficiency and reliability. Also at megawatt power levels, the chopper stage in the frequency converter would probably be a high-risk development item for the same reasons previously presented in the discussion regarding the dc-to-dc PPU.

Three power distribution techniques using low- and high-frequency, and single- and three-phase distribution are compared in Table 3 . Based on this evaluation, the low-frequency approach was selected. It has the lowest mass, highest efficiency, and on the basis of complexity it was judged to have the highest reliability and lowest development costs. While its power quality is not as good as a high-frequency system, it was considered adequate for both ion and MPD engine applications. The low-frequency architecture was designated the reference configuration and component models based on it were developed to support the creation of a future Fortran based model of a PMAD system. This PMAD subroutine will be included in a Fortran program being developed by NASA LeRC for the purpose of conducting system level trade studies on a complete NEP vehicle. 
TABLE 3. Low- versus High-Frequency Comparison for Ion and MPD Thrusters."

\begin{tabular}{|c|c|c|c|c|c|c|}
\hline \multirow[b]{2}{*}{ Parameter } & \multicolumn{2}{|c|}{$\begin{array}{c}\text { Low Frequency } \\
\text { (Altemator Frequency) }\end{array}$} & \multicolumn{2}{|c|}{$\begin{array}{l}\text { Single-Phase } \\
\text { High Frequency }\end{array}$} & \multicolumn{2}{|c|}{$\begin{array}{l}\text { Three-Phase } \\
\text { High Frequency }\end{array}$} \\
\hline & Ion & MPD & Ion & MPD & Ion & MPD \\
\hline Mass & $\begin{array}{c}48,350 \mathrm{~kg} \\
1.68 \mathrm{~kg} / \mathrm{kWe}\end{array}$ & $\begin{array}{c}50,450 \mathrm{~kg} \\
1.75 \mathrm{~kg} / \mathrm{kWe}\end{array}$ & $\begin{array}{c}68,020 \mathrm{~kg} \\
2.36 \mathrm{~kg} / \mathrm{kWe}\end{array}$ & $\begin{array}{c}69,170 \mathrm{~kg} \\
2.40 \mathrm{~kg} / \mathrm{kWe}\end{array}$ & $\begin{array}{c}67,880 \mathrm{~kg} \\
2.36 \mathrm{~kg} / \mathrm{kWe}\end{array}$ & $\begin{array}{c}68,470 \mathrm{~kg} \\
2.38 \mathrm{~kg} / \mathrm{kWe}\end{array}$ \\
\hline Efficiency (\%) & 95.0 & 95.1 & 88.4 & 88.6 & 88.5 & 88.6 \\
\hline Power Quality & Poorest & Poorest & Much Better & Much Better & Best & Best \\
\hline Complexity & Lowest & Lowest & $\begin{array}{l}\text { Much More } \\
\text { Complex }\end{array}$ & $\begin{array}{l}\text { Much More } \\
\text { Complex }\end{array}$ & $\begin{array}{c}\text { Most } \\
\text { Complex }\end{array}$ & $\begin{array}{l}\text { Most } \\
\text { Complex }\end{array}$ \\
\hline
\end{tabular}

2PMAD values based on three channels providing a total of $30 \mathrm{MWe}, 150$ meter main transmission line length, $8000-\mathrm{Vrms}$ transmission voltage, and $100^{\circ} \mathrm{C}$ electronics coldplate temperature.

\section{HIGH-TEMPERATURE ELECTRONICS ANALYSIS}

Using the low-frequency PMAD system for a reference, an initial analysis of HT electronics was conducted to assess their system mass benefit. Although the use of HT electronics will reduce the mass of the electronics radiator, a reduction in efficiency also normally occurs and this will cause the mass of the power source to increase. Analyses were conducted by developing algorithms relating efficiency to temperature, and using them to estimate the electronics coldplate temperature that would yield the minimum power system mass. Because HT semiconductor materials are in the early stages of development, the operating characteristics of proposed devices are largely undefined. Therefore, their operating characteristics at higher temperatures were estimated by extrapolating from present silicon-based device operating data. This approach is probably optimistic because the primary material under consideration, silicon carbide (SiC), exhibits lower electron and hole mobility than silicon and thus would be expected to have a poorer efficiency (Powell and Matus 1991).

A four-step process was used to develop algorithms relating component efficiency to temperature: (1) the main elements in a component were identified, (2) their losses were determined as a function of temperature, (3) the losses attributable to each of these elements were calculated for representative components, and (4) algorithms relating efficiency to temperature were developed for components based on their respective loss allocations. The power handling devices in a component are primarily composed of four elements: copper conductors, semiconductors, magnetic materials, and capacitors. Existing temperature-resistance equations, data sheets, and technical papers were consulted to obtain information relating losses to temperature. This data was used to generate algorithms for each of these elements. Loss breakdowns were then obtained for selected components to determine the losses attributable to each of these elements. Based on these loss breakdowns, and the algorithms previously developed for the elements, algorithms were generated for a complete component.

To evaluate the impact of HT electronics on the NEP power system, it was necessary to use specific weights of representative NEP vehicle power sources. Three configurations, a piloted Mars vehicle, a cargo Mars vehicle, and a lunar vehicle were considered. The power sources on these vehicles were assumed to have specific weights of 5,10 , and $20 \mathrm{~kg} / \mathrm{kWe}$, respectively. Figure 3 shows the results of an analysis on a 30-MWe vehicle with a 3-channel PMAD architecture. It is important to note that the mass penalty shown along the $\mathrm{Y}$-axis, although large, actually represents a small percentage of the total power system mass. For example, the lightest NEP vehicle would probably weigh about $200,000 \mathrm{~kg}$; hence, a mass penalty of $5,000 \mathrm{~kg}$ represents only $2.5 \%$ of the total system mass. Therefore, the mass impact of HT electronics appears to be relatively small. For all three cases, the lowest mass system occurs when the electronics coldplate temperature is at or below $200^{\circ} \mathrm{C}$. In fact, vehicles with heavy power sources will optimize at relatively low temperatures because the efficiency reduction occurring at higher temperatures results in a substantial power source mass penalty.

\section{CONCLUSIONS}

This study determined that a low-frequency PMAD approach was best for multimegawatt NEP vehicles utilizing either Brayton or K-Rankine power conversion cycles. This approach, because it is based on the altemator three-phase output and uses the alternator voltage and frequency directly for transmission, is less complex. It was compared with dc and high-frequency approaches and it had the lowest mass, highest efficiency, and on the basis of complexity it was judged to have the highest reliability and lowest development costs. 


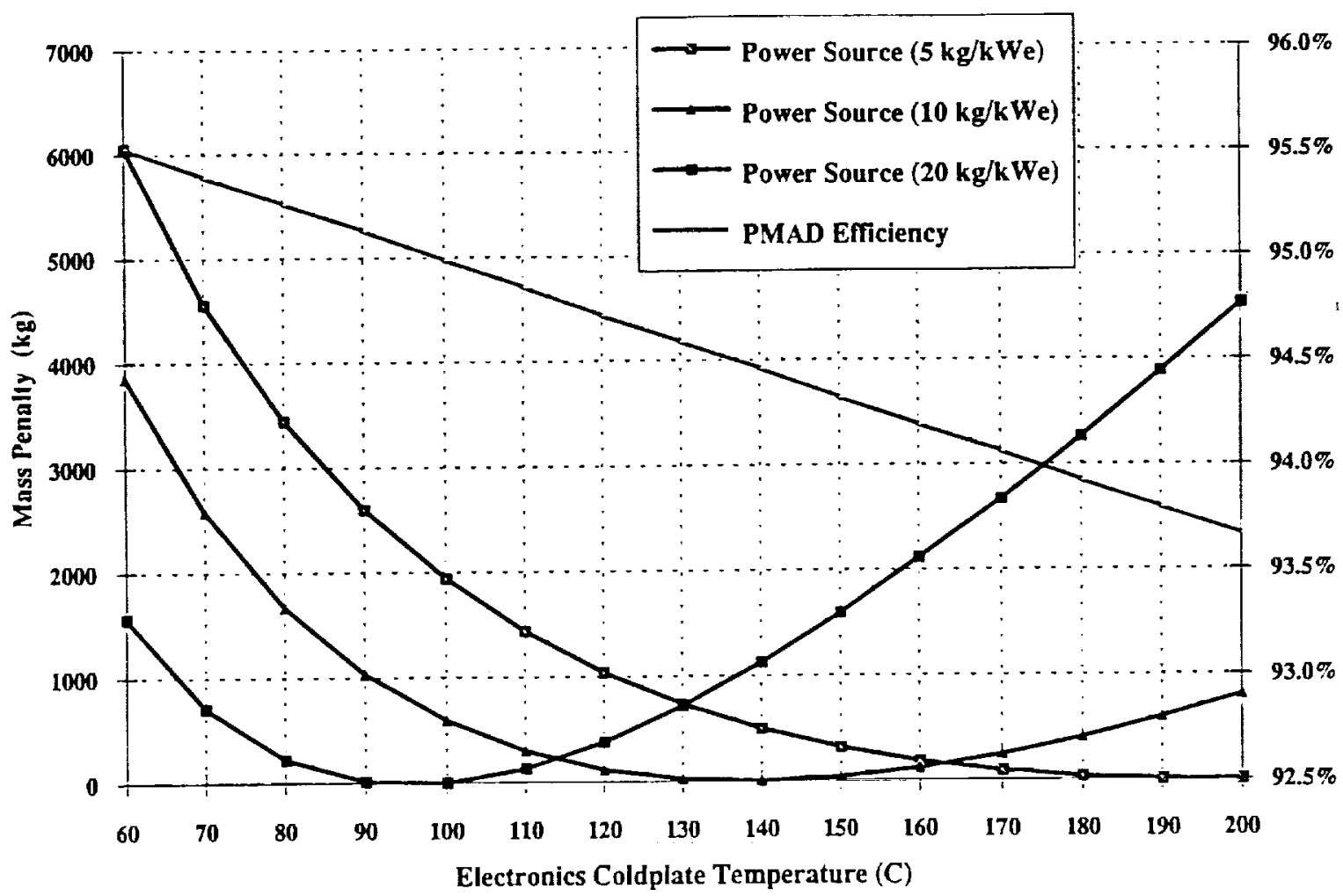

FIGURE 3. Power System Mass Change versus Electronics Coldplate Temperature.

Although the power quality of a low-frequency system is probably not as good as with a dc or high-frequency system, it should be adequate for both ion and MPD thrusters. The low-frequency architecture will be used as the reference for future NEP PMAD studies.

An analysis of component designs operating at coldplate temperatures ranging from 333 to $473 \mathrm{~K}$ indicated the minimum power system mass would occur at coldplate temperatures at or below $473 \mathrm{~K}$. Because the PMAD system end-to-end efficiency declined as the coldplate temperature was increased, a larger power source was required to compensate for the added losses. The resulting increase in power source mass offset the reduction in electronics radiator mass as the coldplate temperature approached $473 \mathrm{~K}$. Based on this analysis, which only considered the impact of efficiency on system mass, it appears specialized silicon semiconductor constructions, such as silicon on sapphire, will be suitable for realizing most of the mass benefits of higher coldplate temperatures. However, it is important to realize that the operating characteristics of HT devices are poorly defined and it was necessary to use extrapolations derived from silicon-based device data to estimate their characteristics. Consequently, it is difficult at this time to determine their true impact. Furthermore, this analysis did not consider other beneficial features of HT devices. For instance, these devices can certainly withstand higher radiation levels and at moderate temperatures they may also provide higher reliability.

\section{Acknowledgments}

This work was sponsored by NASA LeRC under Contract NAS3-25808. The author would like to thank Jim Gilland of NASA LeRC for the technical support he provided on ion and MPD thrusters.

\section{References}

Gilland, J. H., R. M. Mcyers (1990) "Multimegawatt Electric Propulsion System Design Considerations," in Trans. 21st International Electric Propulsion Conference, held in Orlando, FL, 18-20 July 1990.

Meisner, J. W. (1991) "Power Conditioning Assessment for Nuclear, Solar Electric Propulsion," Rockwell International, Rocketdyne Division, 6633 Canoga Ave., Canoga Park, CA.

Powell, J. A., L. G. Matus (1991) “Silicon Carbide, A Semiconductor for Space Power Electronics," in Trans. 8th Space Nuclear Power Systems Symposium, held in Albuquerque, NM, 6-10 January 1991. 